\title{
A pesquisa intervenção em psicologia da educação e clínica: pesquisa e prática psicológica
}

\author{
Heloisa Szymanski \\ Pontifícia Universidade Católica de São Paulo \\ Vera Engler Cury \\ Pontifícia Universidade Católica de Campinas
}

\begin{abstract}
Resumo
Este estudo integra reflexões acerca do ato de pesquisar a partir dos trabalhos de pesquisa e supervisão de estágios realizados por duas docentes vinculadas a programas de pós graduação stricto sensu em Psicologia Clínica e Psicologia da Educação. Após breve consideração acerca do método qualitativo aplicado ao campo da Psicologia, o ponto de vista aqui desenvolvido considera que toda a investigação psicológica implica sempre uma intervenção, na qual tanto participante como pesquisador são afetados pela situação de pesquisa. Pesquisas que acompanham a implementação de práticas educativas e clínicas em instituições educacionais e de saúde têm sempre um caráter de intervenção e desencadeiam um processo de criação e adequação de uma metodologia de pesquisa apropriada aos fenômenos estudados em seus contextos naturais, respeitados o rigor dos procedimentos, o compromisso de construção do conhecimento científico, a ética da prática profissional e a responsabilidade social de oferecimento de serviços de qualidade para a população. Acrescentam-se exemplos de estudos levados a efeito por ambas as autoras.
\end{abstract}

Palavras-chave: pesquisa em instituição; pesquisa intervenção; pesquisa em saúde e educação; prática psicológica e pesquisa; atenção psicológica, atenção psicoeducativa.

\begin{abstract}
Research and intervention in educational and clinical psychology: scientific investigation and psychological practice. This paper presents some considerations about research methods adopted by the authors in the course of their academic work in graduate programs in Clinical and Educational Psychology. They point out to the need of developing new methodologies adapted to the study of those psychological phenomena in their natural settings. It is presented, therefore, a brief consideration of qualitative methods applied to psychological research and, thereafter, some remarks on the double condition of scientific study and psychological practice observed in the modality of qualitative inquiry called intervention research. Some studies carried out following that methodology are indicated as examples of research routines attached to a psychological practice in education and mental health.
\end{abstract}

Keywords: research in clinical and educational institutions; intervention research; research on psychological practice; psychological care, psychoeducational care

Os caminhos do pensamento do sentido sempre se transformam, ora de acordo com o lugar onde começa a caminhada, ora consoante o trecho percorrido pela caminhada, ora conforme o horizonte que, no caminhar, se vai abrindo no que é digno de ser questionado. (Heidegger, 1954/2001, p. 59)

$\mathrm{O}$ ato de pesquisar os fenômenos em seus contextos naturais, respeitados o rigor dos procedimentos de pesquisa, o compromisso de construção do conhecimento científico, a ética da prática profissional e a responsabilidade social, exige um processo de criação e adequação de uma metodologia de pesquisa apropriada. No caso da investigação psicológica realizada em contextos de prestação de serviços, como clínicas-escolas de universidades, há que se considerar o caráter de intervenção assumido por esse modo de pesquisar.

Tal proposta implica a adoção de uma perspectiva etnográfica em estudos qualitativos, cuja análise de dados constitui uma imersão na natureza mesma dos fenômenos intersubjetivos que emergem das mais diversas modalidades de interação, com ênfase na compreensão da natureza das relações que se estabelecem entre pesquisadores e pesquisados.

É nessa ótica que iremos analisar neste artigo a modalidade de pesquisa qualitativa que chamamos de pesquisa intervenção, que se apresenta com um duplo objetivo de contribuir para o conhecimento científico e oferecer um trabalho 
de cuidado psicológico. Apresentaremos, primeiramente, uma breve discussão sobre pesquisa qualitativa, que é a categoria mais ampla em que se enquadra aquela modalidade.

\section{A pesquisa qualitativa em psicologia}

$\mathrm{O}$ paradigma qualitativo vem do questionamento dos métodos das ciências da natureza aplicáveis às ciências humanas e diz respeito, como lembra Rey (1999), "aos processos implicados na construção do conhecimento, à forma pela qual se produz o conhecimento" (p. 30). A Antropologia, com o desenvolvimento da pesquisa etnográfica, teve uma atuação pioneira no desenvolvimento de um paradigma de pesquisa que passou a considerar a presença do pesquisador como uma condição que ameaçava sua postura de neutralidade e objetividade na obtenção e análise dos dados (Mazzotti,1996; Minayo,1996; Rey, 1999).

Reportando-se a Guba, Rey (1999) apresenta o processo de desenvolvimento do paradigma qualitativo, tendo como pano de fundo a problematização dos conceitos de confiabilidade, validade e objetividade e que traz a questão da legitimação dessa modalidade de pesquisa dentro das ciências sociais.

$\mathrm{O}$ resultado da emergência desses questionamentos e de novos procedimentos em pesquisa social trouxe a reflexão de que novos paradigmas de pesquisa deveriam ser considerados, à luz de novas epistemologias "referentes à relação conhecedor e conhecido" (Mazzoti, 1996, p. 17) e metodologias de "como o conhecimento é construído pelo pesquisador" (p. 17).

O desenvolvimento de uma epistemologia qualitativa tem antecedentes importantes na fenomenologia. Minayo (1996) descreve a fenomenologia e a etnometodologia dentro das ciências sociais, como a sociologia da vida cotidiana e lembra o argumento de Husserl de que os atos sociais têm no significado uma propriedade que não está presente nos fenômenos estudados pelas ciências naturais. Na proposta fenomenológica é apresentada “a) uma crítica radical ao objetivismo da ciência, na medida em que propõe a subjetividade como fundante de sentido; b) uma demonstração da subjetividade como sendo constitutiva do ser social e inerente ao âmbito da autocompreensão objetiva; c) a proposta da descrição fenomenológica como tarefa principal da sociologia" (Minayo, 1996, p. 55). A fenomenologia ampliou o espectro de sua contribuição ao articular suas análises na consideração do social e ao enfatizar a historicidade do fenômeno humano.

Atualmente, uma cisão entre pesquisas de base funcionalista e fenomenológica parece ser a resposta ainda parcial e inacabada da Psicologia ao mundo científico, e a questionamentos em que, de um lado, se postula a manutenção dos chamados "objetividade" e "rigor" científico pela adoção de uma metodologia que visa a análise e medição de eventos e variáveis determinados através de correlações estatísticas, possibilitando generalizações e que mantêm sintonia com estudos normativos, tanto na saúde como na educação. De outro lado, propõe-se a perspectiva metodológica, não menos rigorosa cientificamente, em que a relação interpessoal está inexoravelmente contaminada pela subjetividade dos participantes, contaminação esta que não apenas constatamos, mas que desejamos compreender e fomentar no solo fértil da prática psicológica em educação e saúde e nos estudos sobre a natureza da experiência humana enquanto tal (Banister, Burman, Parker, Taylor, \& Tindall, 1994; Mazzotti, 1996; Minayo, 1996; Rey, 1999; Serrano-Garcia \& Collazo, 1992).

Desde esta crítica ao positivismo e o desenvolvimento de uma nova epistemologia qualitativa, como sugere Rey, houve uma trajetória em que foram se delineando diferentes alternativas metodológicas tanto de coleta de dados como de análise. Essas críticas, iniciadas na década de 50, produziram uma reformulação do paradigma positivista e uma sistematização do paradigma qualitativo.

Um resultado positivo do debate quantitativo/qualitativo foi a emergência de novas práticas de pesquisa, como alternativas ao modelo hegemônico de pesquisa, ditado pela psicologia norte-americana do início do século, e a grande contribuição metodológica resultante da elaboração de instrumentos que possibilitavam a expressão livre dos sujeitos, respondendo a demandas decorrentes das transformações que vêm tendo lugar no mundo desde a década de 60 .

Na psicologia, nos movimentos divergentes de uma visão naturalizada e positivista do fenômeno humano, a fenomenologia, segundo Rey, teve uma influência muito grande nos autores humanistas como Rogers, Maslow e Allport, que iniciaram um questionamento ao positivismo, em especial à fragmentação do fenômeno humano, na consideração da perspectiva do outro e na consideração do contexto desse outro.

Acrescente-se que começou, por essa via, um questionamento do próprio papel do pesquisador, agora incorporado à situação de pesquisa. Carl Rogers (1976), num artigo escrito em 1955, no auge de uma ideologia funcionalista em que o positivismo científico era hegemônico no cenário acadêmico norte-americano, admitia:

À medida que adquiri experiência como terapeuta, desenvolvendo a excitante e gratificante experiência de psicoterapia, e trabalhando como investigador científico, apto a descobrir parte da verdade sobre a terapia, tornei-me progressivamente consciente da lacuna entre esses dois papéis. Quanto melhor terapeuta me tornava (como acredito que aconteceu), mais vagamente me apercebia da minha completa subjetividade quando estava no melhor da minha função. E, ao me tornar um melhor investigador, rigoroso e mais científico (como acredito que aconteceu), senti um desconforto crescente quanto à distância entre minha objetividade rigorosa como cientista e minha subjetividade quase mística, como terapeuta. (p.125)

Questionamentos como esse de Rogers sobre as formas de produção do conhecimento revigoraram não só as maneiras de se obter os dados como, e principalmente, o próprio conhecimento do fenômeno humano, do ponto de vista psicológico.

Moustakas (1994) resume os pontos convergentes em pesquisas qualitativas, cujos principais modelos incluem estudos etnográficos, fenomenológicos de tipo hermenêutico ou empírico e heurístico: 
(a) estudos qualitativos cuja temática versa sobre a natureza e essência da experiência humana, enquanto tal;

(b) foco na totalidade da experiência, ao invés de uma preocupação com a determinação de seus objetos ou partes;

(c) busca por significados e essências da experiência humana e não por medidas e explicações causais;

(d) descrições das experiências obtidas em conversas formais ou informais e entrevistas, resultando em depoimentos ou relatos na primeira pessoa;

(e) valorização dos dados da experiência como imperativos para uma compreensão do comportamento humano e como evidência para investigações científicas;

(f) formulação de questões e problemas que reflitam o interesse, envolvimento e comprometimento pessoal do pesquisador; (g) visão da experiência e do comportamento como uma relação integrada e inseparável do sujeito com o objeto e das partes com o todo.

Como se pode observar nos itens arrolados por Moustakas, a análise da experiência ocupa um lugar central em todas elas. Etimologicamente o termo vem do latim experientia, significando prova, ensaio, tentativa (Instituto Antônio Houaiss, 2001, p.1287), que é a acepção do termo nas ciências experimentais. $\mathrm{O}$ dicionário aponta também o significado de experimentação e experimento para o termo, na conotação científica. Na filosofia, o dicionário nos informa que significa "qualquer conhecimento por meio dos sentidos". Comportando diferentes significados, temos também: "forma de conhecimento abrangente, não organizado, ou de sabedoria adquirida de maneira espontânea durante a vida"; "prática"; "forma de conhecimento específica, ou de perícia adquirida por meio de aprendizado sistemático". No dicionário Webster (1996, p. 681) encontramos outros significados ${ }^{1}$ : "uma instância particular de encontrar ou submeter-se a alguma coisa", "a observação, encontro ou sujeição a coisas geralmente como elas ocorrem ao longo do tempo", "conhecimento ou sabedoria prática obtida com aquilo que se observou, encontrou ou submeteu-se". É interessante que o termo tem ao mesmo tempo um significado de produzir um fenômeno para estudá-lo de forma controlada, neutra e quantitativa e um outro sentido que remete ao subjetivo, ao encontro de si com o mundo, a um conhecimento que se consolida com a prática. $\mathrm{O}$ que é comum, tanto na raiz etimológica como nos significados que foram se desenvolvendo, é o encontro com o fenômeno, no caso da pesquisa, provocado pelo pesquisador, de diferentes maneiras e com diferentes interpretações, dependendo da filiação epistemológica daquele.

No que diz respeito ao desenvolvimento da pesquisa Polanyi (1969) afirma:

É costume atualmente representar o processo de investigação científica como o estabelecimento de uma hipótese seguido por sua subseqüente testagem. Não posso aceitar estes termos. Toda pesquisa verdadeiramente científica começa com o esbarrar [do pesquisador] em um profundo e promissor problema e isto em si já é metade da descoberta. (p. 98)

E, mais adiante, continua: "visualizar um problema é ver alguma coisa que embora escondida pode tornar-se acessí- vel. (...) É apoderar-se de um conhecimento incipiente que apaixonadamente luta para vir a ser validado. Eis o poder heurístico de um problema.” (p. 110).

A questão e as relações com a pessoa do pesquisador, portanto, constituem a abertura essencial do processo de pesquisar. A questão em si determinará se um passo autêntico e instigante foi aberto ou não, e se ele sustentará a curiosidade, o envolvimento e a participação do pesquisador com energia e recursos internos, ao longo de todo um processo que demandará tempo, paciência e disciplina.

E aqui nos deparamos com um dos momentos mais difíceis para um pesquisador iniciante. Feild (1979) esclarece:

O que impede você de formular uma verdadeira pergunta? Nunca tinha me ocorrido que a maioria das assim chamadas questões que eu tinha formulado anteriormente eram meras demandas espontâneas. Elas não se baseavam na verdade em estudos ou experiência científica. Agora, após alguns anos de prática, posso sentir a questão dentro de mim, mas ainda assim não consigo chegar às palavras certas... encontrar a questão exata pode ser um processo difícil e sutil. Uma palavra colocada numa determinada parte de uma sentença pode produzir uma resposta totalmente diferente daquela que obteríamos se tivesse sido colocada em outra parte da mesma sentença. Temos que aprender a ser tão precisos com nossas questões de forma que a resposta seja o mais simples e clara possível. (p. 142)

O passo seguinte, que instiga e apavora o pesquisador, consiste em transformar a dúvida inicial em autoconhecimento e, assim, em autoconfiança. Ele tem que evoluir para um estado ativo de conferir certo nível de credibilidade básica ao seu processo interior, ao deixar-se levar pela questão inicial e transformar-se no primeiro sujeito da pesquisa, testando em si mesmo a pergunta disparadora que fará aos participantes hipotéticos, aqueles que convidará a participar como sujeitos (ou co-participantes) do estudo. Isto exige o reconhecimento da importância de uma busca pessoal interiorizada e coloca um valor positivo no conhecimento decorrente dela, como requisito para a compreensão das mais diversas experiências humanas. Portanto, o processo aqui explicitado não pode ser apressado, ou determinado previamente. Ele exige a presença total, a honestidade, a maturidade e a integridade do pesquisador que não apenas deseja intensamente saber e compreender, mas está internamente disponível para comprometerse num longo processo de imersão e concentração focalizada em relação a uma questão central, arriscando-se a abrir em si mesmo dores e dúvidas que podem levá-lo a uma transformação pessoal que o espreitará sempre como uma possibilidade numa jornada como esta.

A validação de uma pesquisa desta natureza reside em verificar se o desvelamento de determinada experiência humana, orientado pela hermenêutica, comunica e sistematiza compreensivamente, de maneira viva e precisa, os significados e sentido da mesma. E este julgamento é feito pelo próprio pesquisador, que é a única pessoa a percorrer todo o processo, desde a formulação inicial da questão até a síntese final, a partir de si mesmo e dos co-participantes que se tornaram companheiros numa parte da viagem. Ele retorna conti- 
nuamente à questão e aos dados brutos para certificar-se de que seus resultados caminham coerentemente com os elementos advindos das fases anteriores, apresenta-os, quando possível, à consideração dos participantes, num amplo processo de diálogo entre os dados obtidos, as análises e o conhecimento produzido na área.

Nessa perspectiva, o ato de pesquisar guarda semelhança tanto com o processo da psicoterapia como com o educativo, considerados como um esforço disciplinado e apaixonado do cliente/educando pelo autoconhecimento em direção à autonomia pessoal e conhecimento do mundo. $\mathrm{O}$ pesquisador deve adotar esta mesma postura de disponibilidade que se inicia com a humilde constatação do próprio desconhecimento e, paradoxalmente, com uma intuitiva confiança em seus recursos pessoais para compreender e deixarse levar no fluxo de seu próprio turbilhão de incertezas e curiosidade. Recupera em si mesmo o caminhar trôpego da criança em direção à conquista de si e do mundo. Tanto o pesquisar como os resultados das pesquisas científicas são desdobramentos advindos do crescimento do pesquisador como ser humano, artífice de si mesmo, a serviço da humanidade num processo de mão dupla que demanda uma ética pessoal e intransferível tornando-o responsável direto pela transformação da sociedade.

\section{A pesquisa ação e pesquisa participante}

Ardoino (1988), em artigo em que discute a pesquisa ação como alternativa metodológica e epistemológica, afirma que a pesquisa ação constitui-se em "uma alternativa epistemológica e não somente metodológica" (p.78), pois está em questão uma visão de mundo. Segundo sua compreensão trata-se de uma mudança de paradigma. Distingue as pesquisas que transformam dados do tipo fenômeno em dados científicos daquelas, mais complexas, cujos dados correspondem às práticas sociais. Esse autor distingue prática de fatos, a primeira não sendo redutível aos segundos. Ao afirmar essa distinção,

é a problemática de uma transparência ${ }^{2}$ suposta ou não do objeto de conhecimento que está em questão. Eu entendo por transparência tudo o que pode ser construído, desmontado, reconstruído sem perda das propriedades iniciais do objeto ou do fenômeno; isto se verifica perfeitamente na matemática, na física, na química (...) o mesmo não se dá para um organismo vivo. (p.79)

Para Ardoino, este não pode ser desmontado sem que suas propriedades iniciais ou identidade sejam prejudicadas.

A fortiori, porque isto é ainda muito mais complexo numa pesquisa ação, o objeto de conhecimento caracteriza-se por sua opacidade, opacidade legítima que se recria na medida em que avança a pesquisa. (p. 79) ${ }^{3}$

Para esse autor, tanto a opacidade como os conflitos na construção dos fatos científicos constituem-se em um "elemento fundamental que não podemos eliminar" (p. 79). Citando Dilthey, lembra que, na pesquisa ação, se trata de um paradigma de implicação, e não de explicação, apontando para seu caráter compreensivo. Ardoino aponta para confu- sões, referentes às bases epistemológicas da pesquisa ação, que a levam a ser considerada com depreciação em relação ao que ele chama de pesquisa canônica. Cita também a confusão entre "pesquisa científica, estudo e praxeologia", muitas vezes a pesquisa ação cai na armadilha de valorizar mais a "otimização da ação do que a produção do conhecimento" (p. 80).

Para Ardoino, ao considerar-se a pesquisa ação,

o problema é de articulação de duas modalidades de conhecimento: epistemologia e metodologia, através do que chamarei, na falta de um termo melhor, de uma retirada dos dados dos produtos mesmo da pesquisa ação. (p. 80)

Lembra que, ao contrário da pesquisa quantitativa, clássica, canônica, que enfatiza o controle, a pesquisa ação revela a avaliação. Seibel (1988) sintetiza, afirmando que

Não é suficiente referir-se a alguns objetos e pouco a pouco tratá-los como fatos científicos, com vistas a explicá-los, com uma esperança e perspectiva de transparência. O projeto é mais ambicioso, pois deseja-se co-produzir o sentido e significado de forma compartilhada e aceita pelos parceiros (é o aspecto maiêutico da pesquisa participante), produzir conhecimentos novos fundamentados cientificamente e otimizar a ação em uma perspectiva de transformação. (p. 59)

Zuñiga (1981) refere-se a duas modalidades de pesquisa ação: uma delas inaugurada por Kurt Lewin, durante a Segunda Guerra, dando apoio ao governo americano, de caráter politicamente conservador, mas, mesmo assim provocando, nas palavras de Ardoino (1988), um "escândalo epistemológico" (p.78) e constituindo-se numa reação à separação entre o pensamento e a ação (Dubost, 1988). A segunda visão de pesquisa ação, ligada a um "projeto político crítico, reivindicativo e marginal", tem em Paulo Freire seu segundo fundador (Zuñiga, 1981, p. 40).

O caráter participativo está presente na pesquisa ação tal como a define Zuñiga (1981), começando pela palavra com que designa os "sujeitos": participantes, que devem ser considerados sujeitos ativos, devendo conhecer os produtos da pesquisa e defender os critérios de utilidade para a comunidade ou grupo (p. 35).

Gajardo (1999) aponta a utilização do conceito de pesquisa-ação, a partir da década de 70 do século passado, como tendo se originado de duas vertentes. Uma do campo da sociologia "como reação aos paradigmas predominantes nas ciências sociais, propondo novos caminhos de ação" (p. 23). Citando Fals Borda, aponta para seis princípios desse tipo de investigação, compromissada com movimentos populares: "autenticidade, antidogmatismo, devolução sistemática, retroalimentação de intelectuais orgânicos, ritmo e equilíbrio entre ação e reflexão e, finalmente, desenvolvimento de uma ciência modesta baseada em técnicas dialógicas" (p. 24).

A segunda vertente citada por Gajardo (1999), também denominada investigação ação, foi a educativa que, naquela mesma década de oitenta, apresentou um desenvolvimento nas práticas educativas, com forte influência de Paulo Freire. É explicitamente compromissada politicamente, 
recebendo também as denominações investigação militante e observação militante (p. 37). Foi grande a contribuição de pesquisadores latino-americanos, como Fals Borda, J. Bosco Pinto, Miguel e Rosiska Darcy de Oliveira, para seu desenvolvimento.

Gajardo (1999) aponta o surgimento conceitual e metodológico da pesquisa participante no início da década de oitenta do século passado. Algumas das características definidoras dessa modalidade de pesquisa apresentadas pela autora se sobrepõem às da pesquisa-ação, como o reconhecimento das implicações políticas e ideológicas subjacentes, a mobilização de grupos com vistas à mudança, a busca de relações igualitárias de poder. Esse tipo de pesquisa supõe uma troca intersubjetiva entre todos os participantes, incluindo o pesquisador, uma mudança definida em consenso e uma proposta de se criar soluções, na consideração da experiência do grupo e à luz do conhecimento científico. SerranoGarcia e Collazo (1992) afirmam que "o processo participante na investigação nasce do esforço de concretizar a promoção do ser humano de forma participante e organizada" (p. 285).

Essas considerações divergem da argumentação de Thiollent (1987) de que os partidários da pesquisa participante se preocupam mais com o papel do investigador na situação investigada do que na questão do agir ${ }^{5}$, reduzindo-a a uma técnica de observação participante. Reconhecendo que pesquisa ação e pesquisa participante sejam tidas como a mesma coisa por vários autores, Thiollent (1999) afirma que

existem diversos tipos de pesquisa participante e diversos tipos de pesquisa ação. Uma clara distinção é necessária. A pesquisa ação é uma forma de pesquisa participante, mas nem todas as pesquisas participantes são pesquisa ação. (p. 82)

Para ser ação, Thiollent põe como exigência a participação de grupos organizados, ou parte deles, com objetivos emancipatórios e de desenvolvimento de conscientização sócio-política. Como foi indicado acima, entretanto, esta foi definida como uma das características de pesquisa participante.

Brandão (1981) refere-se às diferentes denominações que a pesquisa participante assumiu: "observação participante, pesquisa participante, investigação participativa, auto-senso, pesquisa popular, pesquisa dos trabalhadores, pesquisa confronto" (p.15), mas todas elas com um caráter tanto de produção de conhecimento como de compromisso social. Borda (1981) define a pesquisa participante como pesquisa ação, na vertente oposta de Kurt Lewin, referindo à pesquisa da ação comprometida com as necessidades de populações "mais carentes nas estruturas sociais contemporâneas" (p. 43).

O termo participação merece alguma consideração. $\mathrm{O}$ dicionário (Instituto Antônio Houaiss, 2001) nos diz os seguintes significados do termo participar, entre outros: "fazer saber, comunicar, informar, partilhar, associar-se pelo sentimento ou pensamento". O antepositivo part tem o significado de "dar, fornecer". Esse significado está presente quando se considera, na pesquisa participante, a necessidade de partilhar, com todos os que fazem parte da mesma, todos os seus momentos, desde a eleição do objeto de estudos, coleta de dados e, principalmente, resultados. Tal procedimento não impede um aprofundamento de reflexões teóricometodológicas, que tanto podem ser traduzidas para a linguagem de todos os participantes, como adotar a forma convencional de comunicação científica. Já o significado de "associar-se pelo sentimento ou pensamento" aponta para a condição de compromisso social entre pesquisadores e demais participantes.

Para Gohn (1993), participação em ações de interesse social é vista como um sentimento de que "os indivíduos têm valor e são necessários para alguém, quando percebem sua própria contribuição, que têm um lugar na sociedade, que são úteis e valorizados por alguém” (p. 28), e também como uma "luta para melhores condições de vida e pelos benefícios da civilização" (p.14). No caso de uma pesquisa que tenha objetivos de oferecer subsídios para uma melhor qualidade de vida a todos, tais significados valem para todos os participantes e estão associados a sentimentos de pertencimento e responsabilidade social, que inclui o compromisso do cientista com a comunidade acadêmica.

Os autores podem divergir a respeito da classificação dessas diferentes modalidades de pesquisa, inauguradas pela pesquisa-ação, mas há concordância quando se fala na heterogeneidade que elas assumiram. Outro ponto em que há concordância é que, mesmo ao considerar-se a questão valorativa e política, há necessidade de rigor teórico e metodológico na modalidade de pesquisa participante e alguns cuidados devem ser tomados, tais como: não negar o papel da reflexão teórica e epistemológica e não cair no paradoxo de exercer o poder do conhecimento. Veiga (1985) ressalta a necessidade de manter a vigilância epistemológica, quanto à aplicabilidade e conveniência de se utilizar tal proposta de investigação e, em especial, o cuidado de garantir o caráter público dos conhecimentos produzidos por essas pesquisas, divulgando-as no meio científico e exercitando sempre a postura crítica em relação às questões teóricas e metodológicas.

\section{Pesquisa intervenção e prática psicológica}

Intervenção é um termo que é mais conhecido pelo seu sentido autoritário e impeditivo de livre expressão, tal como “ingerência de um indivíduo ou instituição em negócios de outrem [...] interferência do Estado em domínio que não seja de sua competência" (Instituto Antônio Houaiss, 2001). Mas, vindo do latim interventio, onis "abono, fiança, garantia", tem também os significados de "estar entre, sobrevir, assistir". O dicionário "Aurélio" (Ferreira, 1999) apresenta uma definição que mais se aproxima da ação do pesquisador na modalidade de pesquisa intervenção participante: "interpor os bons ofícios”. O dicionário de sinônimos e antônimos (Instituto Antônio Houaiss, 2003) mostra como antônimos os termos abstenção, desinteresse, isenção, indicativos da atitude oposta à de pesquisadores que utilizam sua prática como locus de pesquisa. Lembrando, entretanto, o antigo significado de intervenção, como abono, fiança, garantia, deve ser apontada a necessidade de se criar uma relação de confiança entre todos os participantes da pesquisa, principalmente se esta é resposta a uma demanda de indivíduos ou grupos. 
Para Serrano-Garcia e Collazo (1992), os processos de investigação e intervenção são simultâneos, pois, durante um processo de pesquisa "desde o momento em que uma pessoa começa a fazer indagações, altera, de forma mínima ou máxima o ambiente e as pessoas que a rodeiam" (p. 218).

Uma das autoras deste trabalho (Gomes-Szymanski, 1988) conscientizou-se da condição de intervenção na pesquisa em psicologia com seres humanos, quando em sua pesquisa de doutorado, uma das participantes, na última entrevista "começa falando do tanto que se sentiu ajudada: (...) antes criava encrenca com tudo que o marido fizesse (...) e agora, ela via a coisa com muito mais clareza" (p. 455). Afirmou, ainda, que "se quiséssemos continuar visitando-os seria um prazer, mas que não precisava mais, porque aquela crise havia passado, graças à nossa ajuda" (p. 456). Na perspectiva de pesquisadores, os procedimentos se resumiam a "apenas" ouvir o que a participante tinha para dizer sobre sua vida familiar, como parte da coleta de dados para a pesquisa, mas seu depoimento revela que uma escuta interessada foi experienciada como ajuda, trazendo transformações na vida da família, constituindo-se, assim, numa intervenção.

Como dizem Serrano-Garcia e Collazo (1992), referindose à área de ciências humanas, a aceitação da idéia de que toda pesquisa implica uma intervenção é particularmente válida para aquelas que apresentam uma intencionalidade de mudança. Essa autora ressalta que, além da simultaneidade da intervenção e pesquisa em projetos que objetivam uma mudança, há que se considerar igualmente respeito e consideração com as pessoas que participam da investigação. Isto envolve informar os participantes, oferecer serviços, se solicitados, considerar os problemas e soluções no contexto da comunidade ou grupo, explicar com detalhes os objetivos da pesquisa, planejar com as mesmas os esquemas de ação social. Com essas considerações pode-se entrever o caráter participante desse tipo de investigação.

Dubost (1988) refere-se ao que chama de recherche impliqué como uma forma de pesquisa-ação, contemporânea da clínica em saúde mental, tendo seu início no século XIX e aparecendo

cada vez que os homens tentaram refletir sobre sua práxis a fim de elaborar os princípios, as propriedades, os efeitos, as condições, os limites, os sentidos. Mais precisamente, o fenômeno recherche impliqué emerge quando os profissionais, especialistas de uma determinada área, se recusam a reduzir sua atividade a pura técnica. (p. 44)

Dubost aponta que toda prática que tenha por meta uma mudança, e cita várias áreas de atuação, como educação, saúde, demografia, urbanismo, "representa uma ocasião de reconexão dos enfoques de descoberta e de ação" (p. 45).

Levy (2001), ao comentar a ampliação e transformação do significado de clínica, aponta para as seguintes vertentes renovadoras daquela prática:

a psicanálise freudiana [que] renovou inteiramente, ao mesmo tempo, a aproximação do paciente e a prática científica e a psicologia da Gestalt, a teoria de campo e a pesquisa ação lewiniana, de inspiração fenomenológica, da mesma forma [que] correntes em psicologia e em psicologia social, contribuíram igualmente para aprofundar a noção de intervenção clínica (pp. 11-12).

Esse autor aponta também para a contribuição de pesquisas realizadas por antropólogos e sociólogos em comunidades restritas, e psicólogos trabalhando em organizações industriais, a partir da terceira década do século passado, no que ele chamou de clínica social, constituindo não só novas práticas profissionais, como de pesquisa. Esse movimento provocou ecos na própria universidade, no sentido de construir-se uma "universidade crítica das ciências humanas", de inspiração alemã, "que seria um local de contestação da ordem estabelecida, rejeitando, especialmente, o corte entre disciplinas, assim como a clivagem social entre teóricos e práticos, entre estudantes, professores e pesquisadores" ( $\mathrm{p}$. 13). Estabelece-se o que Levy chama de démarche clínica:

Mais do que um conjunto de métodos e de técnicas, este se define como um posicionamento global em relação ao outro, mas também em relação ao saber e sua elaboração; nesse sentido, coloca em novos termos a questão das relações entre pesquisa e ação ou entre teoria e prática. (p. 19)

Referindo-se ao trabalho de profissionais em instituições, chamados por ele de clínicos, Levy (2001) aponta para as pressões sofridas por eles, decorrentes da complexidade das demandas. Tal situação os levou a incluir a reflexão sobre suas práticas e saberes como um cuidado para não reproduzirem o que o autor chama de "condutas submetidas a sobredeterminações sociais ou psicológicas” (p. 81). A participação, entretanto, da vida de uma organização ou instituição traz uma riqueza de informações que não aparece em situação de laboratório. Daí o surgimento de novas práticas de pesquisa.

Por se tratar de demanda do grupo, a intervenção tem, para este, na maior parte das vezes, o sentido de prestação de serviço em psicologia. O sentido de investigação científica se constitui quando o trabalho é oferecido por pesquisadores engajados em projetos de uma instituição de pesquisa (o diferencial é esse?) Sim, na medida em que a pesquisa deve seguir os padrões propostos pela comunidade científica, em especial no que se refere à comunicação dos resultados. Podese, em determinadas situações de atuação profissional, emprestar elementos da atitude de pesquisa, como era proposto na década de 60 na formação de professores, por exemplo, mas a pesquisa a que nos referimos nesse texto é a associada a instituições de pesquisas. Creio que a questão da pesquisa decorrer de demanda do grupo esclareceu-se acima. A aceitação da situação de pesquisa pode tornar-se uma contrapartida ao serviço oferecido sem ônus financeiro ao grupo solicitante e o transforma em usuário/parceiro.

A condição dupla de serviço psicológico e investigação científica obriga o pesquisador a uma sujeição tanto às normas da ética da pesquisa com seres humanos como às da prática psicológica. Exige conhecimentos teóricos e metodológicos tanto da prática da pesquisa como da profissional e, principalmente, a consideração dos usuários/participantes como pessoas que são focos de cuidado, co-cons- 
trutores do significados e não "objetos" ou "sujeitos" de uma pesquisa.

Essa modalidade de pesquisa preenche os princípios da epistemologia qualitativa apontados por Rey (2000) de que o conhecimento é uma produção construtivo-interpretativa, o processo de produção de conhecimento tem um caráter interativo e a significação da singularidade pode ser considerada como nível legítimo da produção de conhecimento.

Nobre (1999), ao concluir suas considerações sobre avaliação genealógica como um método qualitativo de se pesquisar, afirma:

não é o psicólogo que vai consertar o outro, fazê-lo enxergar de outra forma, mas a produção de sentidos que vai sendo instituída por todos, nos diversos encontros. (...) O genealogista não pesquisa somente para conhecer, mas também para transformar. A transformação é inerente à investigação genealógica e ao conhecimento produzido. (p. 86)

\section{Pesquisa intervenção na saúde mental}

$\mathrm{O}$ interesse pelo tema da atenção psicológica clínica oferecida à população em instituições de saúde derivou da participação de uma das autoras em um Grupo de Trabalho interinstitucional da Associação Nacional de Pesquisa e PósGraduação em Psicologia (ANPEPP), denominado "Práticas psicológicas em instituições: atenção, desconstrução e invenção", que gerou no ano de 2002 um outro Grupo de Pesquisa, este integrado por pesquisadores da Pontifícia Universidade Católica de Campinas e certificado junto ao $\mathrm{CNPq}$ sob o título: "Atenção psicológica clínica em instituições: prevenção e intervenção". Também foi fruto de um processo de desenvolvimento desta mesma temática em dissertações e teses realizadas por orientandos do Programa de Pós-graduação em Psicologia, mais recentemente com trabalhos de campo levados a efeito no contexto da Clínica-Escola da Faculdade de Psicologia como parte de uma linha de pesquisa identificada como "Tratamento e intervenção psicológica".

Para Wertz (1998), a Psicologia Humanista, a qual tem orientado muitos dos estudos citados acima, encontra-se em uma crise que pode ser atribuída a fatores de ordem social, ou seja, por seu caráter inicial de protesto, tendeu a afastar-se das instituições ou de tudo que fosse institucionalizado. Este autor afirma que o momento atual deve ser de um retorno ao convívio institucional, até mesmo para um resgate do impacto da Psicologia Humanista para a sociedade, buscando desenvolver novas pesquisas e uma melhor interlocução com os psicólogos em geral.

A questão do método tem emergido nesses estudos como um problema que demanda reflexões, assim como a necessidade de se desenvolver alternativas que permitam uma validação interna das pesquisas, dada a complexidade dos contextos naturais. Como vimos, os estudos qualitativos visam a natureza e não a extensão dos fenômenos e, quando realizados em instituições, devem ser criteriosamente rigorosos quanto à caracterização das condições das mesmas e dos diversos cenários onde a atenção psicológica será traduzida sob a forma de serviços de saúde mental.
A complexidade da situação de pesquisa em instituições prestadoras de serviços de saúde mental pode ser exemplificada pela situação de implantação de serviços de plantão psicológico. Mahfoud (1999) propõe que este seja definido a partir de três vertentes: a da instituição que oferece o serviço; a do profissional disponível para o não-planejado e a do cliente que busca um auxílio para sua necessidade emergente. A instituição será responsável pela sistematização do serviço; o profissional plantonista deverá ser capaz de conviver satisfatoriamente com o não-planejado; e o cliente encontrará no plantão um ponto de referência e um auxílio para momentos de dificuldade. Pode-se acrescentar mais uma vertente: a do pesquisador, que deverá manter-se fiel à atitude científica, dentro da metodologia qualitativa de investigação, com as características que esboçamos acima. Ao mesmo tempo em que se busca um cuidado metodológico para a pesquisa, há que se considerar as intrincadas situações institucionais que se colocam. É preciso manter a

necessária lucidez quanto à ideologia vigente, impedindo que essa prática sirva aos interesses daqueles que pretendem, pela multiplicidade de modelos de atendimento, apenas mascarar as diferenças e ludibriar a população, substituindo a necessidade real de tratamentos psicológicos pelo oferecimento de serviços e técnicas de caráter amadorístico e sem embasamento teórico. (Cury, 1999, p. 137)

Portanto, responder à demanda institucional não supõe submissão a critérios outros que não derivados de uma ética profissional e pessoal sobre o objeto da atenção psicológica efetivada nas instituições e os da ética de pesquisa em psicologia com seres humanos.

Como adequar esta discussão nascida no campo das aplicações de técnicas psicoterápicas, ou de intervenções psicológicas em geral, às formas de investigação? Na busca de compreensão acerca da problemática suscitada acima, realizou-se um estudo (Cury, 2003) com o objetivo de vislumbrar novas perspectivas a partir de uma análise de pesquisas acadêmicas recentes, desenvolvidas por pesquisadores que participam de programas de intervenção na área da saúde. Procurou-se caracterizar o caminho metodológico efetivado por pesquisadores em estudos de tipo qualitativo, cuja temática e contexto referem-se a intervenções psicológicas clínicas em instituições de saúde, visando sistematizá-los para possibilitar uma análise e o levantamento de alternativas metodológicas aplicáveis ao campo.

Uma das autoras efetivou, juntamente com um aluno do Mestrado em Psicologia Clínica da PUC/Campinas, Renato Zini, um levantamento de pesquisas de campo dos últimos três anos, de relevância para o tema estudado, de forma a analisar os passos compreendidos na metodologia adotada. Foram priorizados estudos brasileiros apresentados sob a forma de teses e dissertações defendidas em programas stricto-sensu credenciados junto à CAPES, incluindo: duas universidades católicas e duas universidades públicas estaduais do Estado de São Paulo, duas universidades federais e uma universidade católica do Estado de Pernambuco. Cerca de 41 pesquisas foram analisadas. 
Procedeu-se uma investigação com ênfase na perspectiva do método, consistindo em uma análise de elementos metodológicos quanto à sua consistência e coerência em relação aos objetivos enunciados e aos resultados obtidos. Priorizou-se a análise de pesquisas de caráter qualitativo e exploratório levadas a efeito em diferentes contextos de saúde mental pública, tais como ambulatórios, setor de isolamento de pediatria em um hospital público, unidade de saúde do SUS, escola de medicina, clínica-escola de psicologia, centro de saúde, domicílios de usuários do SUS, hospitais psiquiátricos, comunidades terapêuticas. Nesses estudos tornaram-se participantes: usuários do serviço público municipal, pacientes internados em hospitais gerais, residentes de medicina, acompanhantes de usuários em sala de espera, mães de crianças internadas, gestantes, agentes de saúde, psicólogos clínicos, médicos, estudantes de medicina e de psicologia, grupos de idosos, grupos de obesos, pacientes soro positivos, membros do grupo de psicóticos anônimos, crianças e adolescentes atendidos em unidades especializadas ambulatoriais.

Os objetivos das pesquisas analisadas versaram sobre: modelos e procedimentos de intervenção médica e psicoterapêutica; questões afetivas, psicossociais e associadas ao sentido de doenças como câncer e AIDS e respectivo tratamento; questões existenciais relativas ao processo de desenvolvimento, envolvendo crianças, adolescentes e idosos; práticas psicológicas preventivas; atenção psicológica associada ao sofrimento decorrente da exclusão social.

De um modo geral, esses estudos mostraram uma ênfase em investigar aspectos relacionados às intervenções clínicas e seus elementos, atendo-se a avaliar a eficácia dos atendimentos, ou determinados sintomas, comportamentos ou patologias psíquicas como uma medida de adequação pessoal ou social dos participantes. Especialmente em relação a estudos com pacientes soropositivos, há uma preocupação quanto à formação e representações sociais dos profissionais que exercem os atendimentos clínicos, sejam eles médicos ou psicólogos. Embora tenha estado presente em alguns estudos, constatou-se um decréscimo na importância do estudo das abordagens teóricas adotadas como fatores de eficácia para as intervenções psicológicas, revelando um deslocamento do foco de investigação para os tipos de serviços oferecidos à clientela pelas instituições responsáveis pela saúde pública.

Observou-se, no entanto, a manutenção da hegemonia de um método positivista de investigação, sem que os psicólogos ousassem romper certos paradigmas e "inventar" novas possibilidades de caminhos para apreender aspectos da experiência subjetiva dos participantes.

Da mesma forma, constituiu-se um foco tão estreito de observação e análise das intervenções em si mesmas que foram negligenciados elementos curadores, extra-terapêuticos, extremamente poderosos e presentes nas relações entre os diferentes atores do drama institucional, atendentes, recepcionistas, técnicos e clientes: o efeito positivo decorrente do próprio relacionamento e a benéfica influência do efeito placebo, presente em intervenções de natureza psicoterápica.
O interesse original pela natureza dos fenômenos estudados não garantiu, portanto, a apreensão do todo em relação aos eventos pesquisados.

\section{Pesquisa intervenção na psicologia da educação: uma experiência}

O Grupo de Trabalho da ANPEPP, "Práticas psicológicas em instituições: atenção, desconstrução e invenção", inspirou a constituição, no ano de 2002, de um grupo de pesquisa integrado por pesquisadores da PUC/SP, FURG, UNISO e $\mathrm{UFU}^{6}$ e certificado junto ao CNPq sob o título: "Grupo de pesquisa em práticas educativas e atenção psicoeducacional à escola, família e comunidade", vinculado ao Programa de Estudos em Psicologia da Educação da Pontifícia Universidade Católica de São Paulo. As pesquisas desenvolvidas por esse grupo têm se realizado em meio a um serviço de atenção psicoeducativa para famílias, escola e creche de uma comunidade de baixa renda, da periferia de São Paulo, desde 1992.

Os trabalhos de pesquisa, de iniciação científica, dissertações e teses desenvolvidos por esse grupo de pesquisa, e antes mesmo de sua constituição, seguiram a metodologia de pesquisa intervenção e têm contribuído para o aprofundamento da reflexão sobre a mesma. Tais estudos têm demonstrado que a pesquisa em ambiente natural e inserida numa situação de intervenção psicoeducacional obriga o pesquisador a desenvolver novos métodos de pesquisa, muitas vezes inspirando-se na prática profissional. $\mathrm{O}$ mesmo pode se dar com o inverso: procedimentos de pesquisa constituindo-se em práticas de intervenção, como será indicado adiante.

A proposta ampla de pesquisa e intervenção em práticas educativas e apoio psicoeducacional tem se realizado em torno de três eixos: famílias, creche/escola e comunidade. Ao longo do tempo configuraram-se as seguintes modalidades de intervenção ${ }^{7}$ : na família: entrevistas familiares com construção de genograma ou com elaboração de história de vida; encontros coletivos bimensais; plantão psicoeducativo. Na creche a atuação inclui: apoio pedagógico; observação participante em sala de aula, encontros coletivos e plantão psicoeducativo. Na escola oferece-se: apoio pedagógico (em instalação) e plantão psicoeducativo. Na comunidade são oferecidos: apoio pedagógico a educadores de uma ONG, apoio psicoeducativo e plantão para uma cooperativa comunitária.

$\mathrm{O}$ trabalho de intervenção junto às famílias, creche/escola e comunidade tem como meta a apresentação da prática dialógica e participativa, segundo proposta de Paulo Freire, vista como alternativa ao autoritarismo e o uso da força como medida disciplinar. Uma de suas características é a prática reflexiva e esta tem sido adotada nos próprios procedimentos de pesquisa.

A reflexão no processo de pesquisa se constitui através da devolução contínua de informações ao usuário/participante. Os encontros de devolução dos dados, para informar os resultados da análise aos participantes, são cuidadosamente planejados de forma a propiciar uma condição favorável de comunicação aos participantes. Esse modo de agir 
acabou por inspirar a elaboração de novos procedimentos de intervenção indicando um movimento de influência da pesquisa na intervenção. Observou-se que o momento de devolução tem se constituído numa oportunidade de reflexão para todos os envolvidos, pesquisadores e participantes. Tais procedimentos contribuíram também para a elaboração de uma proposta reflexiva de procedimento de coleta de dados, em especial, a entrevista reflexiva (Szymanski, 2002).

Os resultados das pesquisas apontam para uma consolidação da parceria entre a universidade e comunidade, expressa na solicitação de projetos de apoio à família, a cooperativas, a grupos de jovens, a educadores da creche e escola (Ferreira, 2003; Martins, 1999; Ribeiro, 2002). Essa parceria inclui oferecimento de condições de trabalho e apoio de infra-estrutura (providenciar local, horário, agendamento de atividades) e acompanhamento de todos os projetos oferecidos por parte da liderança comunitária. Como conseqüência, temos aceitação e assimilação crescente dos serviços de apoio psicológico. Foram se desfazendo preconceitos referentes a serviços psicológicos como "coisa de loucos" e a busca de serviços, em especial do plantão psicoeducativo, tem apresentado crescimento contínuo (Ribeiro, 2004). Por solicitação da comunidade foi instalado um serviço de atendimento psicoterápico.

Nas pesquisas realizadas junto às famílias tem-se observado a prevalência da crença na eficácia de práticas autoritárias para evitar a delinqüência (Szymanski, 1998), mas começou a desenvolver-se uma preocupação em substituir práticas autoritárias e violentas por outras, de cunho dialógico (Lima, 2003; Martins, 2002; Prado, 2003; Serio, 2003) e uma gradual tentativa de mudança.

\section{Considerações finais}

A pesquisa intervenção mostrou-se como uma possibilidade, tanto de formação de profissionais como de pesquisadores, além de oferecer serviços psicológicos para uma população mal atendida pelos serviços públicos. A implementação dessa modalidade de pesquisa qualitativa possibilitou o desenvolvimento de procedimentos de pesquisa que se converteram em práticas. $\mathrm{O}$ inverso também ocorreu, indicando o fértil intercâmbio entre pesquisa e prática, além da contribuição teórica que esse diálogo proporcionou.

\section{Referências}

Ardoino, J. (1988). La recherche-action: alternative méthodologique ou épistemologique. In M. Hugon \& C. Sebel (Orgs.), Recherches impliquées, recherches action: le cas de l'éducation (pp. 78-80). Bruxelas: De Boeck.

Banister, P., Burman, E., Parker, I., Taylor, M., \& Tindall, C. (1994). Qualitative methods in Psychology: a research guide. Filadelfia: Open University Press.

Bohart, A. C., \& Tallman, K. (1996). The active client-therapy as self-help. Journal of Humanistic Psychology, 36(3), 7-30.

Borda, O. F. (1981). Aspectos teóricos da pesquisa participante: considerações sobre o significado e o papel da ciência na participação popular. In Brandão, C. R. (Org.), Pesquisa participante (pp. 42-62). São Paulo: Brasiliense.

Brandão, C. R. (1981). Pesquisa participante. São Paulo: Brasiliense.

Brandão, C. R. (1999). Repensando a pesquisa participante. São Paulo: Brasiliense.
Cury, V. E. (1999). Plantão psicológico em clínica-escola. In M. Mahfoud (Org.), Plantão psicológico: novos horizontes (pp. 115-133). São Paulo: Editora Companhia Ilimitada.

Cury, V. E. (2003). As incursões de uma atenção psicológica clínica em instituições de saúde mental pública. Manuscrito não-publicado, Pontifícia Universidade Católica de Campinas, Campinas.

Dubost, J. (1988). La question de la spécificité dês recherches-action selon lês champs. In M. Hugon \& C. Sebel (Orgs.), Recherches impliquées, recherches action: le cas de l'éducation (pp. 44-45). Bruxelas: DeBoeck.

Feild, R. (1976). The invisible way. Nova York: Harper \& Row.

Ferreira, A. B. H. (1999). Novo Aurélio - Dicionário da Língua Portuguesa Século XXI (3 $3^{\underline{a}}$ ed.). São Paulo: Nova Fronteira.

Ferreira, A. P. (2003). Um estudo sobre interação criança-criança em uma creche comunitária. Relatório de Iniciação Científica não-publicado, CEPE-PUCSP, São Paulo.

Gajardo, M. (1999). Pesquisa participante: proposta e projetos. In Brandão, C. R. (Org.), Repensando a pesquisa participante (pp. 15-50). São Paulo: Brasiliense.

Gohn, M. G. (2001). Conselhos gestores e participação sociopolítica. São Paulo: Cortez.

Gomes-Szymanski, H. (1988). Um estudo sobre significado de família. Tese de Doutorado não-publicada, Pontifícia Universidade Católica de São Paulo, São Paulo.

Heidegger, M. (1954/2001). Ensaios e conferências (Trad. E. C. Leão). Petrópolis: Vozes.

Instituto Antônio Houaiss de Lexicografia (2001). Dicionário Houaiss da Língua Portuguesa. Rio de Janeiro: Autor.

Levy, A. (2001). Ciências clínicas e organizações sociais. Belo Horizonte: Autentica/FUMEC.

Lima, A. P. (2003). A relação adulto criança no contexto familiar. Relatório de Iniciação Científica não-publicado. CEPE-PUCSP.

Mahfoud, M. (1999). Plantão psicológico: novos horizontes. São Paulo: Editora Companhia Ilimitada.

Martins, E. A. (1999). Interação criança-criança em jogos cooperativos. Relatório de Iniciação Científica não-publicado, CEPE-PUCSP, São Paulo.

Martins, E. (2002). O brincar como uma prática educativa na família. Tese de doutorado não-publicada, Pontifícia Universidade Católica de São Paulo, São Paulo.

Mazzotti, A. A. J. (1996). O debate atual sobre os paradigmas de pesquisa em educação. Cadernos de Pesquisa, 96, 13-23.

Minayo, M. C. S. (1996). O desafio do conhecimento. Rio de Janeiro: Hucitec. Moustakas, C. (1994). Phenomenological research methods. Thousands Oaks: Sage. Nobre, A. (1999). Avaliação genealógica. In P. R. M. Menandro, Z. A. Trindade, \& E. B. Borloti (Orgs.), Pesquisa em Psicologia: recriando métodos (pp. 73-87). Vitória: UFES, CAPES, PROIN.

Polanyi, M. (1969). Knowing and being. Chicago: University of Chicago Press. Prado, A. A. R. (2003). A transmissão intergeneracional de práticas educativas; um estudo com história de vida. Relatório de Iniciação Científica nãopublicado, CEPE-PUCSP.

Rey, F. G. (2000). La investigación cualitativa en Psicologia. São Paulo: EDUC.

Ribeiro, F. F. (2004). O plantão psicoeducativo: espaço de reflexão e mudança oferecido às famílias de uma comunidade de baixa renda. Dissertação de Mestrado não-publicada, Pontifícia Universidade Católica de São Paulo, São Paulo.

Ribeiro, M. I. S. P. (2002). O cuidado da criança na relação dialógica educador/educando. Dissertação de Mestrado não-publicada, Pontifícia Universidade Católica de São Paulo, São Paulo.

Rogers, C. R. (1976). Pessoa ou ciência: um problema de filosofia. In Rogers, C. R. Tornar-se pessoa (pp. 177-200). São Paulo: Martins Fontes.

Seibel, C. (1988). Le statut scientifique de la recherche action. In M. Hugon \& C. Sebel (Orgs.), Recherches impliquées, recherches action: le cas de l'éducation. Bruxelas: De Boeck. 
Serio, R. (2003). A transmissão intergeneracional de práticas educativas: um estudo com genograma. Relatório de Iniciação Científica não-publicado. CEPE-PUCSP.

Serrano-Garcia, I., \& Collazo, W. R. (1992). Contribuciones portorriqueñas a la psicologia social-comunitaria. Rio Piedras: Editorial de La Universidad de Puerto Rico.

Szymanski, H. (1998). Práticas educativas familiares e o sentido da construção da identidade: autoritarismo, violência e identidade negativa. Relatório de pesquisa não-publicado. PEPGPE/PUCSP.

Szymanski, H. (2002). A entrevista na pesquisa em educação: a prática reflexiva. Brasília: Plano.

Thiollent, M. (1987). Crítica metodológica. investigação social e enquete operária. São Paulo: Polis.
Thiollent, M. (1999). Notas para o debate sobre pesquisa ação. In Brandão, C. R. (Org.), Repensando a pesquisa participante (pp. 82-103). São Paulo: Brasiliense.

Veiga, L. da (1985). Educação, movimentos populares e a pesquisa participante: algumas considerações. In F. R. Madeira \& G. N. Mello. Educação na América Latina: os modelos teóricos e a realidade social (pp. 187-202). São Paulo: Cortez \& Autores Associados.

Wertz, F. J. (1998). The role of the humanistic movement in the history of Psychology. Journal of Humanistic Psychology, 38(1), 42-70.

Webster's New Universal Unabridged Dictionary (1996). Nova York: Barnes \& Noble.

Zuñiga, R. (1981). La recherche action et li controle du savoir. Revue Internationale d'action communautair, 5/45, 35-44.

3 Tradução das autoras.

4 Itálicos do autor.

5 Talvez referindo-se à observação participante como instrumento de pesquisa, usado por alguns como sinônimo de pesquisa participante.

6 Pontifícia Universidade Católica de São Paulo, Fundação Universidade do Rio Grande, Universidade de Sorocaba e Universidade Federal de Uberlândia.

7 Sempre na forma de um projeto de iniciação científica, mestrado ou doutorado.

Heloisa Szymanski é professora na Pontifícia Universidade Católica de São Paulo. Endereço para correspondência: Rua Maranhão, 531, Apto. 52; São Paulo, SP; CEP 01240-001. Tel/fax: (11) 3666-0895. E-mail: hszymans@pucsp.br Vera Engler Cury é professora na Pontifícia Universidade Católica de Campinas. E-mail: wavey@ dglnet.com.br ou pos.psico@puc-campinas.edu.br 